\title{
Improving Middle and Secondary Teacher Preparation for Inclusion: First Lessons Planned, Lessons Learned
}

\author{
Denise R. Foley \\ Worcester State University, United States of America
}

\begin{abstract}
In the US, most students with disabilities are fully included; that is, $80 \%$ or more of their education takes place in general education classrooms. Middle and secondary teachers generally feel unprepared to teach students with disabilities and other learning vulnerabilities, especially as they are just entering the field. Changes in curriculum, instructional methods and field-based practical experiences in a training program in a state with high rates of student with special needs, and other learning differences and vulnerabilities are described. Results of the culminating assignment, Differentiated Lessons incorporating Universal Design for Learning principles and evidence-based strategies suggest that expectations for student learner outcomes were met; however, there is room for improvement. Crosscurriculum exemplars are provided. Next steps including planned adjustments to narrow the teacher preparation versus reality gap are discussed.
\end{abstract}

\section{Introduction}

Of the 50 million students enrolled in public schools across the United States, 13 percent (over 6.6 million) are eligible for special education services [1]. Great strides have been made towards inclusion such that the majority of students with special needs receive half to ALL of their instruction and related services in general education settings [2]. Though on both conceptual and practical levels inclusion is the norm in public schools, new and early-career teachers consistently describe how ill-prepared they feel to teach students with special needs in regular classrooms $[3,4]$. This is especially true for teachers at the middle and secondary levels $[5,6,7]$.

From their first days on the job, most US educators are evaluated on their "impact" on student progress across the general curriculum. Common measures of impact include annual national and state competency tests [8]. Further, teachers are evaluated on their "effectiveness" with certain "target" groups of students who are traditionally most at-risk for poor outcomes [9]. These include students from linguistically, racially, culturally and/or socioeconomically diverse backgrounds, and those with high-incidence disorders and disabilities [10].

Though the number and range of specialized needs that students present with in general education classes on a daily basis is well-known and the fact that educators are evaluated on the outcomes of all their students, the literature suggests that teacher preparation programs have not "kept up" in preparing future teachers for these realities [11]. This gap in teacher preparation is an international concern [12].

Reflecting recent, substantial philosophical and pedagogical shifts in a teacher-training program, this paper describes some results of the first offering of courses either modified or specifically created to better prepare future middle and secondary educators to more effectively teach students with special learning and behavioral needs. In addition to describing the instructional methods and materials, practice-based assignments it summarizes the performance relative to expected learner outcomes of pre-service and early career teachers on the culminating course assignment. This was a Differentiated Lesson grounded in evidence-based instructional practices, incorporating the principles of Universal Design for Learning as well as, the specific accommodations and modifications outlined in students' Individual Education Programs (IEPs). Excerpts from exemplar inclusive middle and secondary lessons from across the curriculum, as well as, planned improvements and future directions for the courses are also described.

\section{Literature Review}

\subsection{Educating Students with Disabilities: National Trends}

Though the number (currently over 6.6 million) is nearly double what it was 25 years ago, the percentage of children and youth (currently $13.2 \%$ ) aged 3 to 21 years eligible to receive special education services in the United States under the Individuals with Disabilities Education Act (IDEA), has remained steady since academic year 2000-01 [2]. These children are eligible for special education 
services under one or more of nine disability categories. It should be noted that the term "multiple disabilities is used when the child presents with a disabilities in more than of the other categories but none is determined to be primary." Figure 1 summarizes the percentage of students receiving special education services under each category including multiple disabilities.

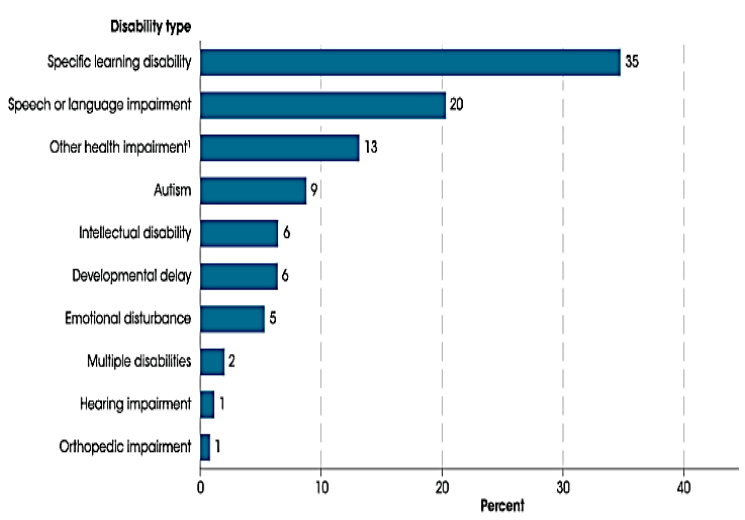

Figure 1. Percentage of children receiving special education services by disability category: $2014-15$

Image: https://nces.ed.gov/programs/coe/indicator_cgg.asp

The primary disability of almost 70 percent of all students eligible for special education services falls into only three of the possible categories. As such, collectively, these three categories of disability are described as "high incidence." Over one-third of students present with specific learning disabilities in reading, written language and/or mathematics. Twenty percent have receptive and/or expressive language impairments. Almost fifteen percent of students are served under the broad "other health impairment" category which includes Attention Deficit Hyperactivity Disorder, Tourette's disorder, sickle cell anemia, asthma and diabetes among other disorders.

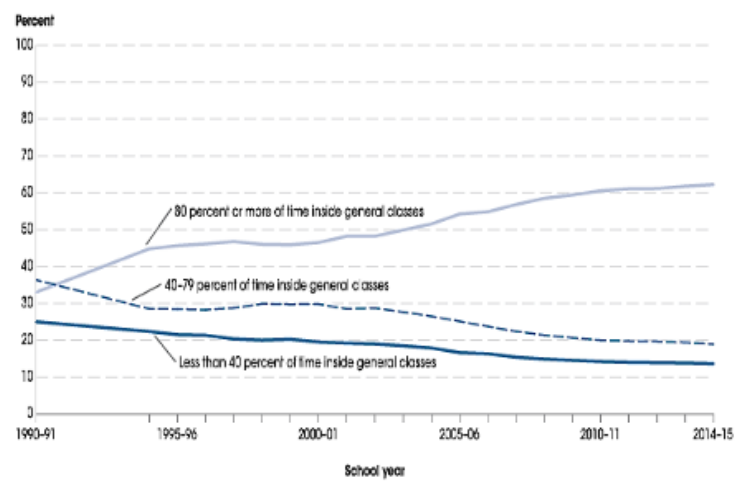

Figure 2. Percentage of US students aged 6-21 by amount of time spent in general education classes Image: https://nces.ed.gov/programs/coe/indicator_cgg.asp
As shown in Figure 2, the percentage of time students with disabilities are educated with their typical peers has steady increased over the past 25 years.

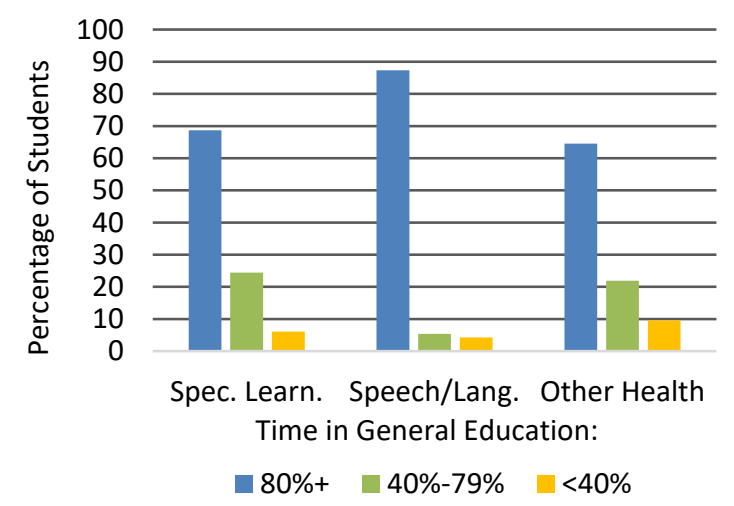

Figure 3. Percentage of US students with high incidence disabilities by percentage general education

Currently, the rate of full inclusion (80\%) for all students with disabilities, across all grade levels is over 60 percent. As shown in Figure 3, students with high incidence disabilities are included in general education classes at even higher rates.

\subsection{Educating Students with Disabilities and Types of Diversity: Massachusetts}

The percentage of students with disabilities receiving special education services in Massachusetts is consistently above the national average and typically ranks among the top three states in terms of rate. Currently, over $17 \%$ of the almost one million students in the state [13]. The rate of inclusion for all students with special needs and those with high incidence disabilities mirror the national averages.

Beyond those eligible to receive direct services under an IEP, many Massachusetts students present with other types of diversity and needs. Figure 4 summaries the percentage of students who are at higher than average risk for difficulties in school due to their membership in select populations highlighted by the Massachusetts Department of Elementary \& Secondary Education (DESE) [14]. 


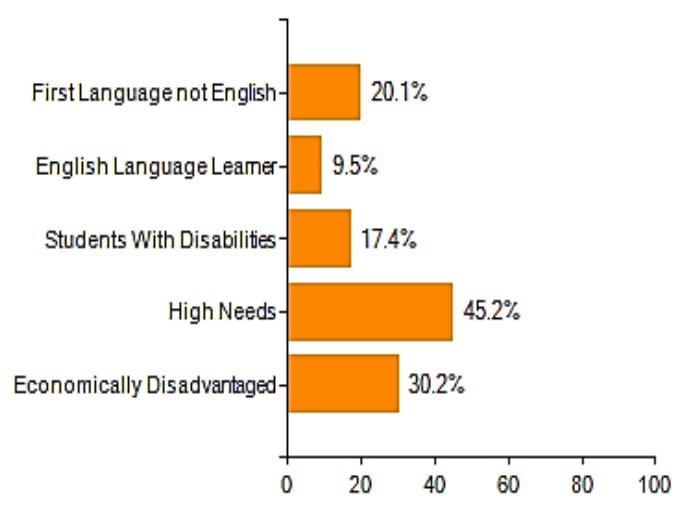

Figure 4. Percentage of MA students in select at-risk populations during school year 2017-18

Image: http://profiles.doe.mass.edu/

These are students: with language differences and English Language learners, are eligible for special education services, live in low socio-economic status homes Students who are members of 1-, 2- 3- or all 4 of those populations are described as having "high needs."

When combined with the $3.2 \%$ of students with disabilities who receive accommodations under Section 504 plans (twice the national average) [15], it becomes abundantly clear that roughly half of all students in the Massachusetts public schools may be considered "at-risk" and require some sort of learning accommodations.

\subsection{Educating Students with Disabilities \& Types of Diversity: The Needs of Teachers}

Learner variability, like that seen in Massachusetts, presents challenges of knowledge, skill and confidence to even the most experienced and skilled general education teachers [3]. Internationally, new and early career teachers, especially those at the middle and secondary levels, consistently report feeling confident in content area knowledge but ill-prepared to meet the range of diverse learning that their students present with [7]. This suggests a "mismatch" between how teachers are traditional prepared and the reality of today's classrooms [16].

Like the majority of teacher preparation programs, WSU has historically followed what Blanton and Pugach [17] term as a "discrete" model, whereby the preparation of special education and general education teachers is separate. The confluence of four factors propelled a move towards a more "integrated" approach to middle and secondary teacher preparation [17]. While licensure for special and general educators remains distinct, faculty worked together to create or adapt course work and field experiences such that general educators learn about special education.

The first and second factors leading to adjustments in the preparation of middle and secondary teachers were based on real-world experience. The first was the feedback from graduates of the program gathered as part of process whereby the WSU teacher preparation program earned national accreditation in 2013 from the Teacher Education Accreditation Council (now part of Council for the Accreditation of Educator Preparation or CAEP). The number one response to the open-ended survey question regarding how the teacher preparation program could improve was to better prepare general education teachers to teach students with special needs in content area classes.

The second influence came from on-going discussions among faculty who had substantial experience in both general and special education at the middle and secondary level across a variety of public school settings.

The third and fourth factors may be categorized as responses to changes made by DESE regarding the evaluation system for all public school teachers and other personnel, as well as, new standards relative to the preparedness of new teachers on their first days "on the job."

Teachers and all support personnel earn one overall summative rating based on two related but sets of criteria: 1) standards for effective teaching practice and 2) educator impact on student achievement. In order to earn an overall satisfactory or very satisfactory rating, teachers MUST be rated as proficient on the Teaching All Students standard. This means that a teacher "uses instructional practices that reflect high expectations regarding content and quality of effort and work, engage all students, and are personalized to accommodate diverse learning styles, needs, interests, and levels of readiness [10]."

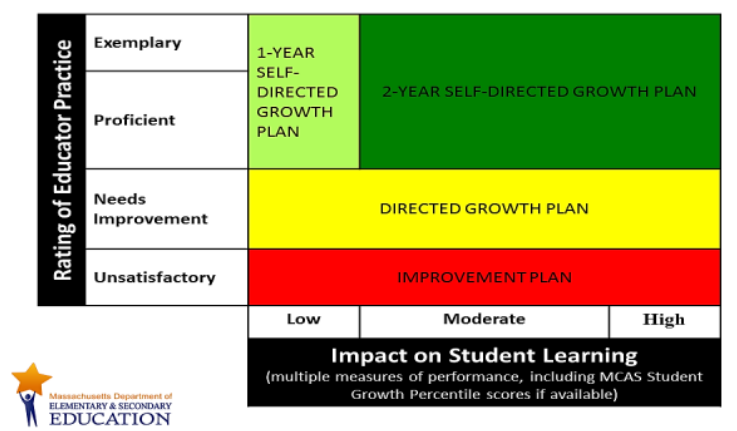

Figure 5. MA summative teacher evaluation model Image: http://www.doe.mass.edu/edeval/model/

Figure 5 highlights relationship of the two criteria (Standards $\mathrm{Y}$ axis; Impact $\mathrm{X}$ axis) relative to the summative rating and the action steps teachers 
must take if their summative rating is not proficient or higher.

In order to earn a summative rating in the "green" section of the Teacher Evaluation Model, teachers must have more than subject area knowledge. They must consistently demonstrate the ability to meet a variety of learning needs in both the planning and delivery of instruction. Further, their students, including the select at-risk populations highlighted in Figure 4 (above), must perform well on various measures of achievement, including state mandated standardized tests.

The final factor propelling us towards a more integrated model of teacher preparation was the recent release of a Guidebook on Inclusive Practice by DESE. This guidebook reflects the conceptualization of inclusive practice refers as "the instructional and behavioral strategies that improve academic and social-emotional outcomes for all students, with and without disabilities, in general education settings [emphasis added, 18]." DESE has stated unequivocally that both pre-service and currently employed teachers should be able to not only articulate the elements of inclusive practice, but also demonstrate them by "using the evidence based frameworks of Universal Design for Learning (UDL), Positive Behavior Intervention and Supports (PBIS), and Social and Emotional Learning (SEL) [18]."

\section{Methodology}

\subsection{Participants}

Participants were individuals seeking initial teacher licensure at the middle (grades 5-8) and/or secondary (9-12) levels, enrolled in three required courses within the teacher preparation program at Worcester State University. Table 1 summarizes the participants' characteristics.

Table 1. Demographics of Respondents $(n=32)$

\begin{tabular}{|c|c|c|}
\hline Variable & $\mathrm{n}$ & Percentage \\
\hline \multicolumn{3}{|l|}{ Gender } \\
\hline Male & 14 & 44 \\
\hline Female & 18 & 56 \\
\hline \multicolumn{3}{|l|}{ Ethnicity } \\
\hline White, Non-Hispanic & 29 & 91 \\
\hline Hispanic & 3 & 9 \\
\hline \multicolumn{3}{|l|}{ Languages } \\
\hline Mono-lingual: English & 28 & 87 \\
\hline Bilingual: English, Spanish & 3 & 10 \\
\hline Bilingual: English, Polish & 1 & 3 \\
\hline \multicolumn{3}{|l|}{ Education Level } \\
\hline Undergraduate & 14 & 44 \\
\hline Post-Baccalaureate & 18 & 56 \\
\hline
\end{tabular}

\begin{tabular}{|c|c|c|}
\hline \\
\hline & & \\
\hline Education: Other & 6 & 19 \\
\hline Employed: Other, F/T Student & 15 & 47 \\
\hline \multicolumn{3}{|l|}{ Licensure Level } \\
\hline Middle School & 2 & 6 \\
\hline Middle \& High School & 8 & 25 \\
\hline High School & 22 & 69 \\
\hline \multicolumn{3}{|l|}{ Content Area } \\
\hline English & 9 & 28 \\
\hline History & 9 & 28 \\
\hline Spanish & 2 & 6 \\
\hline Biology & 2 & 6 \\
\hline General Science & 2 & 6 \\
\hline Health & 3 & 10 \\
\hline Mathematics & 5 & 16 \\
\hline
\end{tabular}

Worcester State University (WSU) is a mediumsized, public university located in Worcester, New England's second-largest city, in central Massachusetts. The WSU teacher preparation program offers both undergraduate and postbaccalaureate level programs individuals seeking initial teacher licensure for grades PreK-12. It is accredited at the state and national levels by DESE and CAEP, respectively.

Participants were mostly white and monolingual in English. There were approximately twenty percent more females than males and twenty percent more post-baccalaureate than undergraduate students. Over two-thirds sought licenses at the high school level, less than ten percent at the middle school level and twenty-five percent sought licenses in content areas that are span middle and high school grades (Spanish and Health). Two-thirds sought licenses in humanities content areas, while one third in the STEM fields (here, Sciences and Mathematics).

\subsection{Intended Outcomes and Procedures}

While there are obvious differences in terms of entrance requirements for each level, the postbaccalaureate and undergraduate teacher preparation course sequence at WSU are very similar. Both are divided into three stages. The first courses are foundational/introductory and field requirements are generally passive observational in nature. The second stage courses focus more on application (i.e., methods and materials, classroom management) with associated field-based, practical, experiences. The final stage is a full time, semester-long practicum in the content and grade level of the license being taught. By the end of that semester, students should have "taken over" and be ready to plan for, instruct and manage a class of diverse learners on their own. The courses that were the focus of this paper are part of the second stage of preparation.

At the undergraduate level, two new courses exploring learning disabilities and other 
exceptionalities and strategies to differentiate curriculum to meet student needs were developed: one focusing on middle school, the other on secondary school. At the post-baccalaureate level, an existing course focusing on general instructional strategies classroom management was adjusted to reflect the realities of the learning and behavior needs of children with disabilities as well as, other special needs in inclusive grade 5-12 classrooms.

The Student Learning Outcomes (SLOs) for the undergraduate and post-baccalaureate courses were written or revised, respectively. At both levels, the concepts and procedures associated with and the responsibilities of general education teachers in Response to Intervention (RTI) models including progress monitoring using curriculum-based assessments were introduced. In addition, as result of their authentic and engaged participation, at the conclusion of this course, it was expected that students would be able to explain or outline:

1. Key terms and concepts that describe special education

2. Laws that govern current practices for educating students with disabilities

3. Process through which a student may become eligible to receive special education services

4. Components of IEP's and 504 plans

5. Roles and responsibilities of the general education teacher in the Special Education eligibility process, as well as the development and implementation of the IEP

6. Characteristics of students with specific high/low-incidence disabilities, and the accommodations that can be made for them

7. Different models of supporting students with disabilities including co-teaching

While a variety of methods and materials were used in the courses, according to students, those which were most impactful towards attaining the above SLOs were the focused observations in inclusion general education, tier 2 and special education classrooms.

The culminating assignment of the course, the Differentiated Lesson, was designed to address the following learning outcomes:

1. Draw on results of formal and informal assessments to plan lessons appropriate for a full range of learners

2. Differentiate learning experiences and assessments to enable all students to progress toward meeting intended outcomes that are rigorous.

In preparation for this assignment, in addition to the focused observations in content area inclusion classrooms at the middle and secondary levels, participants completed and then reflected upon:
1. the actual assessment forms completed by general education teaches as required by DESE in the special education eligibility process ("Educational Assessment Form B" [19]);

2. the most commonly used (in the US) socialemotional-behavioral rating scales completed by general education teachers as part of special education processes; and

3. Multiple high incidence disability simulations using open access resources [20, 21].

The undergraduate and post-baccalaureate students were also given (limited to in-class only) access (by permission) to an actual (sanitized, anonymous) but expired IEP of a middle school student with a communication disorder.

In addition, participants watched videos and reviewed the materials used in actual middle and secondary school general education inclusion classrooms. These lessons and materials were from both open access sites and commercially available resources associated with differentiated instruction and Universal Design for Learning (UDL) [20, 22, 23].

Finally, using a direct instruction/gradual release of responsibility approach, students practiced differentiating elements of DESE model curriculum units [24]. It should be noted that exploration and practice using UDL principles started with a focus on the "why" of learning. In other words, strategies to promote purposeful, engaged learners.

The Differentiated Lesson had several requirements. In addition to writing up their planned lesson on the official WSU template, participants were required to align and analyze various elements of their lessons with each of the nine principles of UDL (Figure 6) as well as, the three elements of differentiated instruction as conceptualized by Tomlinson (content, process, product) [22].

The rubric for the Differentiated Lessons graded each of the nine UDL elements separately. In addition, the lessons were given one holistic rating for the "Teaching All Students Standard" in accordance with DESE Educator Evaluation rubric.

Labels for each level of proficiency reflected those of DESE: Very Limited-Not Evident, Emerging, Proficient and Exemplary. Descriptors for each level of proficiency were also provided.

Undergraduates had the option of working individually or in pairs. They had the option to modify a lesson from one of the DESE model units or create their own reflecting MA Curriculum frameworks for grade level and subject matter where available - there are no curriculum frameworks for health or Spanish. A significant amount of class time (four class periods) was devoted to creating their lessons while getting individualized attention and support from the instructor. 


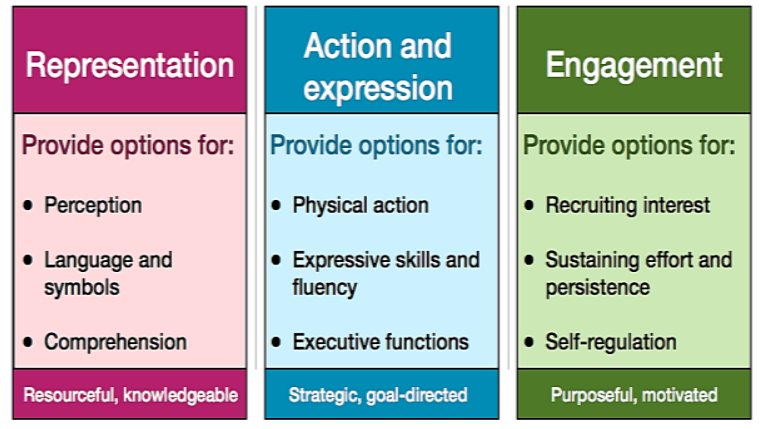

Figure 6. Universal Design for Learning Guidelines 2.0 Image: http://transformlearning.avila.edu/ctl/universal-design-learning/

They presented their lessons to their peers in class. All students provided both contemporaneous, as well as, subsequent anonymous written feedback to each other. Peer feedback, however, was reviewed and graded by the instructor before release to student presenters. Peer feedback was graded also using a rubric with descriptors and examples for levels of specificity, utility, and reflection of course content.

Post-baccalaureate participants also had the option to modify a lesson from a DESE model unit or to develop their own. They developed their own lessons individually and outside of class time. However, consultation with and feedback from the instructor were provided virtually. Also, postbaccalaureates were assigned to pairs to provide feedback during the creation of the lessons. In addition, when one partner presented, the other was required to facilitate the post-presentation discussion and feedback session.

\section{Outcomes}

\subsection{UDL Representation: The "What" of Learning}

As would be expected given their lack of experience and still-limited content area knowledge, the majority of undergraduates struggled with this element of their lessons. Though they universally attempted to present information visually (e.g.: Powerpoint and videos), they relied mostly on lecture and listening as the primary means to "deliver" instruction. That said, there were several outstanding examples of multiple means of representation. Figure 7 is an example of providing multiple means of representing and translating the language and symbols of math word problems which is appropriate for broad range of learner variability Another excellent example of multiple ways of representing the content was how one student-built background knowledge through stories and pictures such that $9^{\text {th }}$ graders with learning disabilities, attention deficits and linguistic and cultural differences to better understand the symbolism in the Lord of the Flies.
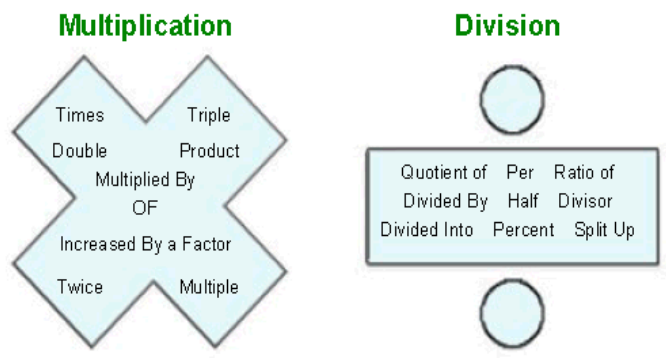

Figure 7. Words and phrases to math symbols Image from: www.math-aids.com

Figures 8 displays a portion of a modified note taker. Other portions of the note taker included sections to "Stop and Think" or "Stop and Predict" and opportunities to activate prior knowledge through words and drawings associated with the term "innocence" as a key theme in the test is loss of innocence.

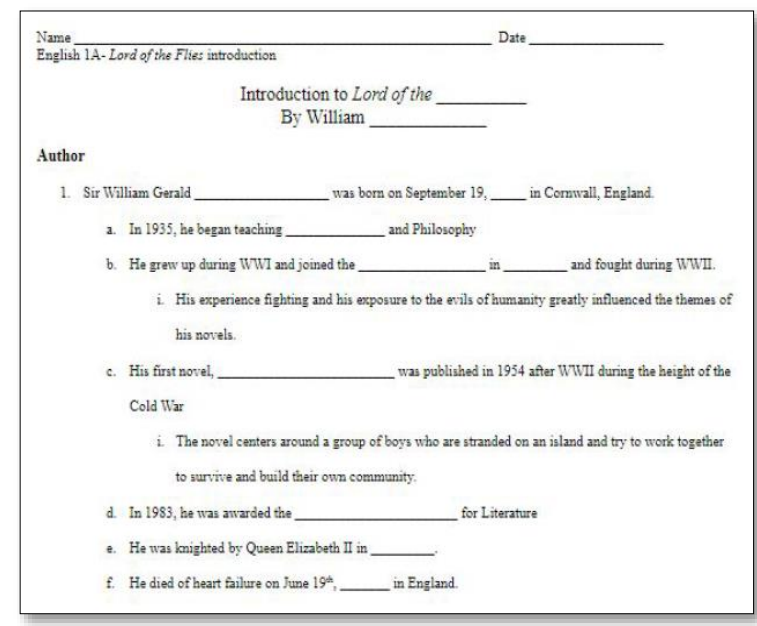

Figure 8. Modified note taker

\subsection{UDL Action/Expression: The "How" of Learning}

Most participants developed multiple options for expression, communication of knowledge and response as part of their middle and high school lessons. Many used interactive game-like technology for example, the popular website Quiletlive.com. However, many also provided "low-tech/no-tech" options like the movement-based activity to find the median shown in Figure 9. This engaging activity provided a foundation for students to demonstrate their understanding across a variety of other median problems that could be completed individually, in pairs or in small groups. 


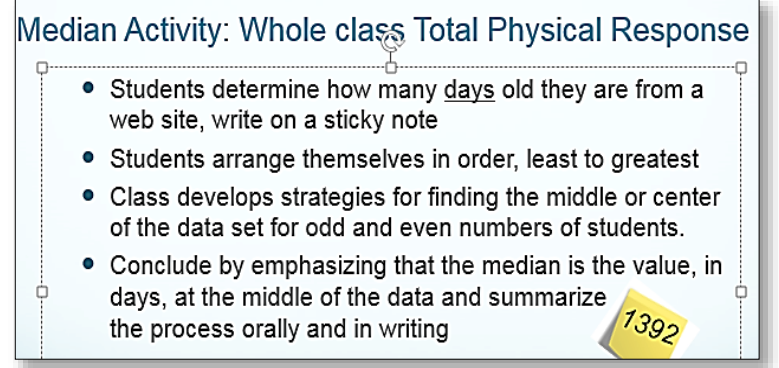

Figure 9. Physical activity built into math problem solving

A minimal-tech example for multiple means of expression was one participant's creative way to not only engage his students in what is often a dreaded task (learning to conjugate verbs), but also to provide scaffolding (visuals, song lyrics) while students responded verbally, in recorded paired conversations, as well as, in writing. After multiple viewings of the Flor Palida music video by Marc Anthony (Figure 10), students then retold (in Spanish) what happened in the video using the past tense of select verbs.

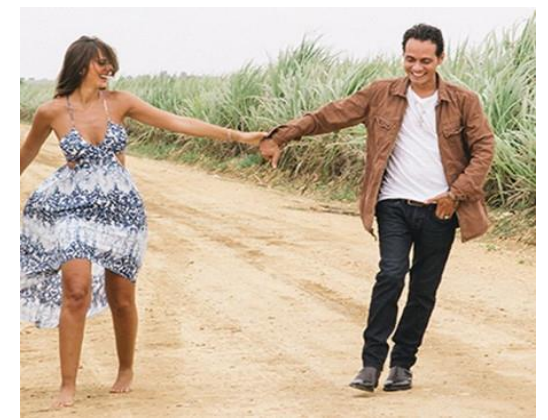

Figure 10. Students told the story of a music video to demonstrate knowledge of conjugated verbs Image: marcanthonyonline.com

\subsection{UDL Engagement: The "Why" of Learning}

Though often addressed last in most discussions of UDL, providing multiple ways to make the content relevant to students is necessary (but of course not sufficient) for them to learn and retain content knowledge and skills, develop higher level thinking skills, problem solve and become more selfdirected, internally motivated learners. Undergraduate and post-baccalaureate participants provided so many wonderful elements that was hard to choose what to include herein.

Images and characters from the Star Wars movies, are considered by many researchers to be among the most enduring and recognizable internationally. The image in in Figure 11 of Darth Vadar reaching out and imploring Luke Skywalker to take his hand was successfully employed to make distant historical events (World War II) relevant and to help make abstract principles like intended and unintended consequences, "power struggle," and nationalism, relatable.

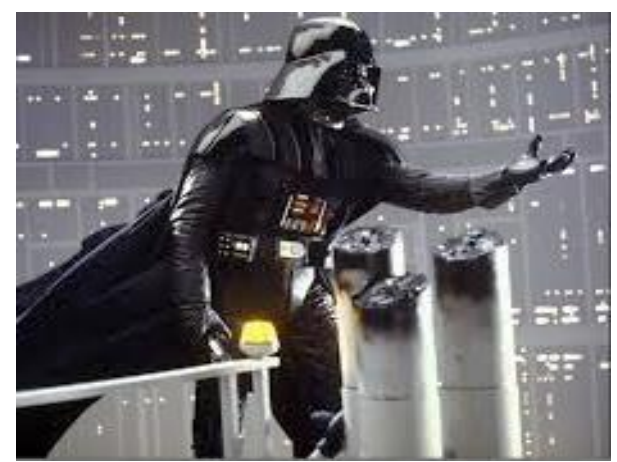

Figure 11. Recognizable fictional character helps students relate to distant events and abstract concepts

The second example of successful engagement comes from a different history lesson that triggered immediate emotional reactions to an activity introducing a distant, dark and seemingly irrelevant period in US history: "McCarthyism" and the "Red Scare." In this activity, students are charged with building a house of cards and given small slips of paper. They are told that one of them will receive a slip with the word "mole" on it. The mole's job is to destroy or otherwise prevent the house of cards from being built. The key is that although no student is actually a "mole," students immediately become suspicious of each other and are convinced that one or more peers is the mole. Accused peers become defensive. Figure 12 is a photo of this very effective activity in process.

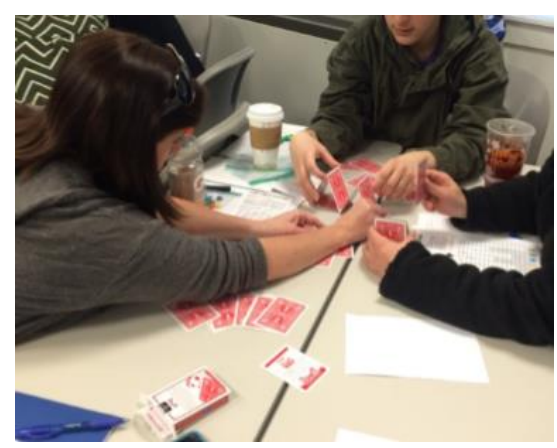

Figure 12. House of cards activity fosters emotional connection to history

\section{Next Steps}

At the end of the semester, students were asked for feedback on how the courses might be improved. Two recommendations were made. First, participants 
wanted opportunities to work with multiple IEPs, especially as they prepared the Differentiated Lesson. Surprisingly, given some of the less-thanpositive comments while they were working on it, participants found the Placement Summary activity to be very valuable. Their second recommendation was to make the due date for that assignment later in the semester. That way, they could better understand the settings they were observing in. The third recommendation arose from instructor reflection. For the first offering of the courses, the grading rubric for the Differentiated Lesson was organized according to the nine UDL principles. To limit student confusion, and improve both peer and instructor feedback, it was recommended that the rubric keep the same elements but be reorganized to reflect the natural sequence of a most lessons: opening, body, closing, assessment, etc.).

When planning for the next semester of the course, adjustments were made to the course to reflect the recommendations. As of this writing, the second semester offering these new/revised courses is in progress. Thus, the results of these adjustments, as well as, overall students learning outcomes are unknown.

\section{Acknowledgement}

While they have chosen to remain anonymous, this author would like to thank the Worcester State University students who participated in the first iteration of the course for granting permission to share their assignments as part of this paper.

\section{References}

[1] U.S. Department of Education, National Center on Education Statistics (NCES) (2017). The Condition of Education: Elementary and Secondary Enrollment. Washington, DC: Author. Retrieved from https://nces.ed.gov/programs/coe/indicator_cga.asp.

(Access date: 3 November 2017).

[2] U.S. Department of Education, National Center on Education Statistics (NCES) (2017). The Condition of Education: Children and Youth with Disabilities. Washington, DC: Author. Retrieved from https://nces.ed.gov/programs/coe/indicator_cgg.asp. (Access date: 12 August 2017).

[3] Rosenzweig, Kate. (2009). "Are Today's General Education Teachers Prepared to Meet the Needs of Their Inclusive Students?" NERA Conference Proceedings 2009. Retrieved from http://digitalcommons.uconn.edu/nera 2009/10. (Access date: 1 September 2017).

[4] Burke, K., \& Sutherland, C. (2004). Attitudes toward inclusion: Knowledge vs. experience. Education, 125(2), 163-172.
[5] DeSimone, Janet R.; Parmar, Rene S. (2006) Middle School Mathematics Teachers' Beliefs About Inclusion of Students with Learning Disabilities. Learning Disabilities Research \& Practice, 21(2), 98-110.

[6] Van Reusen, A. K.; Shoho, A. R.; Barker, K.S. (2001) High School Teachers' Attitudes Towards Inclusion. High School Journal, 84 (2), 7-21.

[7] McClanahan, B. (2008). Help! I have kids who can't read in my world history class! Preventing School Failure, 53(2), 105-111.

[8] Center on Education Policy (2012). State high school exit exams: A policy in transition. Washington, DC: Center on Education Policy, Graduate School of Education and Human Development, The George Washington University

[9] Shriberg, D. (2006). The role of demographics and opportunities to learn in predicting performance on a highstakes test. Journal of Applied School Psychology, 23(1), p59-76.

[10] Massachusetts Department of Elementary and Secondary Education. (2014). Massachusetts model system for educator evaluation. Boston: Author. Retrieved from http://www.doe.mass.edu/edeval/. (Access date: 13 May 2017).

[11] Harvey, M.W., Yssel, N., Bauserman, A.D., \& Merbler, J.B. (2010) Preservice Teacher Preparation for Inclusion: An Exploration of Higher Education TeacherTraining Institutions. Remedial and Special Education, 31 (1), 24-33.

[12] Florian, L. (2008). Special or Inclusive Education: Future Trends. British Journal of Special Education, 35(4), 202-208.

[13] Massachusetts Department of Elementary \& Secondary Education (2017). Report to the Legislature: Annual Report on Students with Disabilities 2015-16. Malden, MA: Author.

[14] Massachusetts Department (2017). Schools and Districts Profiles: State Profile. Retrieved from: http://profiles.doe.mass.edu/general/generalstate.aspx?top NavID=1\&leftNavId=100\&orgcode $=00000000$ \&orgtypec ode $=0$. (Access date: 3 September 2017).

[15] Advocacy Institute (2015). Overall enrollment and 504 students by state. Advocacy Institute Complete 504 analysis. Retrieved from:http://www.advocacyinstitute.org /resources/504analysisCRDC2012.shtml. (Access date: 14 September 2017).

[16] Hardman, M.L. (2009). Redesigning the preparation of all teachers within the framewok of an intergrated program model. Teaching and Teacher Education, 25, 583-587.

[17] Blanton, L.P. Pugach, M.C. (2007, June). 
Collaborative programs in general and special teacher education: An action guide for higher education and state policymakers. Washington, DC: Council of Chief State School Officers.

[18] Massachusetts Department of Elementary \& Secondary Education (2017). Educator effectiveness guidebook for inclusive practice. Malden, MA: Author.

[19] Massachusetts Department of Elementary \& Secondary Education (2018) IEP forms and Notices. Retrieved from: http://www.doe.mass.edu/sped/iep/. (Access date: 1 June 2017).

[20] The IRIS Center (2018). Resource Locator. Nashville, TN: Peabody College, Vanderbilt University.

Retrieved from: https://iris.peabody.vanderbilt.edu/irisresource-locator/. (Access date: 12 January 2018).

[21] Misunderstood Minds (2004). Disability Simulations. Boston, MA: WGBH Educational Foundation. Retrieved from: http://www.pbs.org/wgbh/misunderstoodminds/. (Access date: 14 December 2017).

[22] Tomlinson, C.A. (2014). The Differentiated classroom, Second Edition. Alexandria, VA: ASCD

[23] CAST (2011). Universal Design for Learning Guidelines version 2.0. Wakefield, MA: Author

[24] Massachusetts Department of Elementary \& Secondary Education (2017) Model Curriculum Units. Malden, MA: Author. Accessed from: http://www.doe.mass.edu/candi/model/download_form.asp x. (Access date: 18 November 2017). 